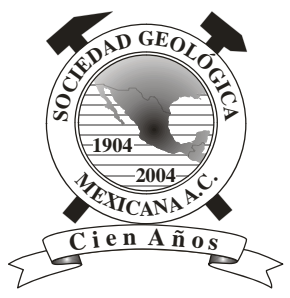

\title{
Reseña:
}

\section{Una nueva historia de la Tierra de Alan Cutler}

\author{
por José Lugo-Hubp
}

Instituto de Geografía, Universidad Nacional Autónoma de México, Ciudad Universitaria, Delegación Coyoacán 04510 México, D.F. lugo@servidor.unam.mx

El geólogo francés Alan Cutler es autor de un libro por demás interesante, resultado una minuciosa investigación que realizó sobre la vida de Nicolaus Steno, quien estableció principios y leyes fundamentales de la Geología en el siglo XVII. Pasaron dos siglos más para que surgiera la geología moderna con los estudios de los escoceses James Hutton (1726-1797) y Charles Lyell (1797-1875).

Nicolaus Steno (o Niels Stensen) nació en Dinamarca en 1638, fue educado en los principios del luteranismo, estudió medicina y destacó por su habilidad para disecar organismos e interpretar su anatomía. Es uno de los hombres notables del siglo XVII que siguieron al Renacimiento, contemporáneo de Boyle, Hook, Leibniz, Newton y Spinoza. El origen de los fósiles fue un tema candente entre los siglos XVI y XVIII. Las explicaciones entonces dominantes eran en el sentido que los fósiles habían nacido y crecido donde se encontraban, o bien eran residuos del Diluvio Universal. Steno comprendió que los fósiles nacieron y vivieron en el mar, y el piso marino se elevó para convertirse en tierra firme, en montañas. Explicó lo que hoy es el abecé de la geología: las capas de roca: “arriba y abajo, continuidad y discontinuidad, inclinación y horizontalidad, lo encerrado y lo que encierra” (p. 124), los principios de la estratigrafía y la geología estructural. Hombre de formación religiosa y creencias arraigadas, siempre buscó una explicación racional al origen de las rocas y los fósiles.

Su obra principal De Solido la culminó en 1668 y fue el tratado de geología más avanzado de su época, aunque trató de correlacionar sus interpretaciones científicas con los textos bíblicos. Para bien, la revisión a cargo de la Iglesia dio un fallo favorable y se publicó en 1669. Con el tiempo Steno se convirtió al catolicismo -hizo la carrera sacerdotal y fue nombrado obispo, cargo que tenía al morir en la pobreza en 1686, a los 48 años. Steno estableció el

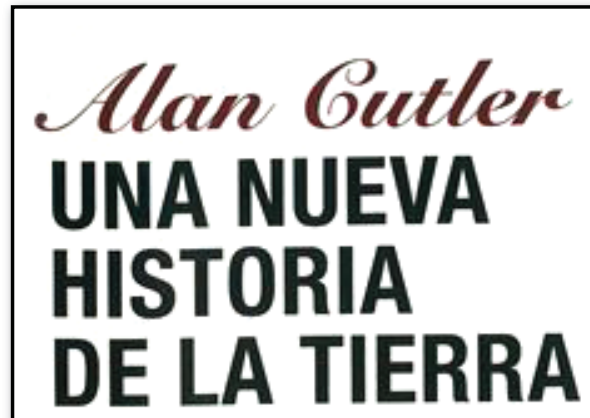

Un relato sobre la ciencia y. Vicolaus fieno, el genio que descubrió la geologia

*El libro de Cutler es maravilloso." The line Howt Grove
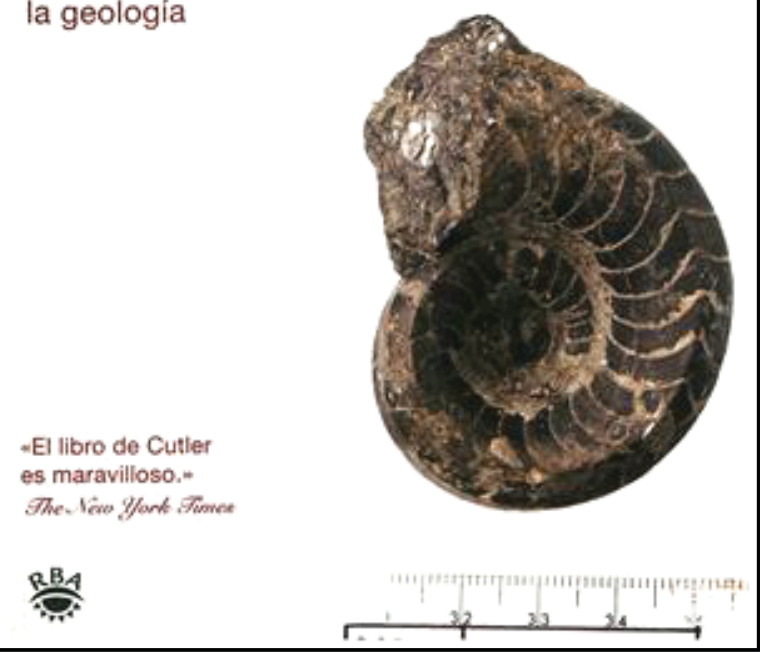

origen de los fósiles marinos, lo que sólo se podía explicar por un tiempo que parecía fantasioso. Profesó su religión sin conflicto propio, ni con la jerarquía eclesiástica. Desde su muerte fue propuesto para la canonización y fue beatificado en 1988.

Alan Cutler escribe una historia amena, no se limita a explicar el aporte al conocimiento que hicieron hombres de ciencia y filósofos del siglo XVII, y comenta, por ejemplo, la relación que mantenía el científico con el rey, el obispo y los colegas, donde lo normal eran los conflictos, y obligaba al estudioso a hacerla de equilibrista para obtener apoyo moral y económico. Por otro lado, parece insuficiente la atención que da a Leonardo da Vinci (1452-1519), quien propuso conceptos geológicos sobre 


\section{Lugo-Hubp}

la erosión fluvial, la transformación global y dio una explicación racional sobre el origen de los fósiles. Aunque sus notables contribuciones se conocieron sólo en el siglo XIX.

El autor también trata un tema fundamental: las teorías científicas revolucionarias del siglo XVIII sobre la evolución de los continentes y los océanos: en un tiempo prolongado las montañas se formaban en el fondo marino, se integraban al continente, que a su vez era cubierto parcialmente por el mar. "Para algunas personas de mentalidad científica las teorías de los océanos universales y los mares migratorios parecían tan fantásticas como los relatos de la Biblia sobre Noé y el arca” (p. 215). Entre ellos hubo hombres de vanguardia como el filósofo Voltaire.

"Hasta que el descubrimiento de la radiactividad aportó un método para medir directamente la edad de las rocas, los críticos más vehementes del tiempo geológico eran los físicos, no los sacerdotes” (p. 220).

Los últimos escritos de Steno no llegaron a publicarse, son desconocidos. Dice el autor que podrían contener conceptos avanzados sobre el tiempo geológico; pudiendo haber sido consumidos por el fuego en un incendio o estarán en algún lugar esperando ser descubiertos (p. 221). Cutler señala lo que al lector resulta obvio: el libro "está pensado para el público general y no tiene la intención de ser una obra académica” (p. 230 ).

Tiene mucha razón el autor al mencionar que los conceptos novedosos sobre el tiempo y la actividad de la Tierra han sido rechazados no sólo por quienes se escudan en creencias religiosas, sino también por científicos contemporáneos. Fueron mayoría los neptunistas de fines del siglo XVIII que daban una importancia superior al océano en la formación de las rocas, prácticamente rechazando la influencia de la actividad interna del planeta, teoría defendida por los plutonistas. En la primera mitad del siglo XIX se dio la lucha de los catastrofistas encabezados por
Cuvier, a la sazón padre de la paleontología, contra los evolucionistas en minoría, en la geología representados por Hutton y Lyell. La obra de Darwin sepultó al catastrofismo, y en el siglo siguiente la historia se repite con Wegener, el autor de la teoría de la deriva de los continentes. El célebre investigador no pudo explicar cómo o por qué se mueven los continentes, y su muerte prematura suspendió la investigación. Los geólogos de la época rechazaron las ideas wegenerianas, pero el estudio del fondo oceánico tras la II Guerra Mundial demostró que su relieve, estructura y edad no eran lo que se suponía, y que había que dar otra explicación de su origen. Así surgió de la tectónica de placas que causó asombro entre numerosos geocientíficos. ¿Habrá en el futuro casos semejantes?

La vida de Steno acerca al lector al nacimiento de la geología en el siglo XVII, lo que hace al libro valioso para los estudiosos de esta disciplina y de otras relacionadas con la Tierra y la historia. A la inversa del principio geológico del actualismo, el conocimiento del pasado facilita la comprensión del presente. Libros como este son de una importancia especial en los países de habla hispana, donde son escasos, sea escritos en nuestro idioma o traducidos de otro. La bibliografía (p. 230-237) incluye más de 70 publicaciones, y sólo 3 de ellas tienen versión en español (indicado en la ficha bibliográfica).

\section{Referencias bibliográficas}

Cutler A. , 2007, Una nueva historia de la Tierra. RBA Libros, Barcelona, 255 p. 